\title{
Association between hyperpolarization-activated channel in interstitial cells of Cajal and gastrointestinal dysmotility induced by malignant ascites
}

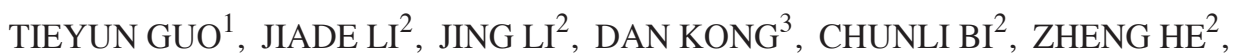 \\ DAI TANG $^{2}$, XIAOMING JIN ${ }^{2}$ and LIANHONG JIN ${ }^{1}$ \\ Departments of ${ }^{1}$ Histology and Embryology and ${ }^{2}$ Pathology, Basic Medical Science College, \\ Harbin Medical University; ${ }^{3}$ Department of Gynecology, The Third Affiliated Hospital \\ of Harbin Medical University, Harbin, Heilongjiang 150081, P.R. China
}

Received July 23, 2015; Accepted November 3, 2016

DOI: $10.3892 / 01.2017 .5652$

\begin{abstract}
Advanced malignant ascites is accompanied by gastrointestinal dysmotility, and patients often feel abdominal pain, abdominal distention, nausea and constipation. Gastrointestinal dysmotility is not only painful for the patients, but it reduces the absorption of nutrients and affects the physical recovery of patients with malignant ascites. It is reported that changes in interstitial cells of Cajal (ICCs) are responsible for the gastrointestinal dysmotility induced by malignant ascites, but the mechanism is not completely understood. The present study observed a significantly decreased expression of ion channels, including hyperpolarization-activated cyclic nucleotide-gated potassium channel 2 (HCN2) and cyclic adenosine monophosphate, in the condition of malignant ascites. Using electrophysiology, it was identified that malignant ascites led to lower amplitude and slower frequency signals in cells of the small intestine. In addition, when ICCs were cultured with malignant ascites in vitro, the expression of HCN2 of ICCs was significantly reduced, and the data of flow cytometry revealed that the $\mathrm{Ca}^{2+}$ concentration of ICCs was also decreased. The results of electron microscopy analysis demonstrated the nuclei of ICCs were pyknotic, and the processes of ICCs were reduced in malignant ascites. The present study suggests
\end{abstract}

Correspondence to: Professor Lianhong Jin, Department of Histology and Embryology, Basic Medical Science College, Harbin Medical University, 157 Baojian Road, Harbin, Heilongjiang 150081, P.R. China

E-mail:wstjlh@126.com

Professor Xiaoming Jin, Department of Pathology, Basic Medical Science College, Harbin Medical University, 157 Baojian Road, Harbin, Heilongjiang 150081, P.R. China

E-mail: jinxm55@163.com

Key words: malignant ascites, interstitial cell of Cajal, hyperpolarization-activated channel, small intestine, gastrointestinal dysmotility the small intestinal dysmotility caused by malignant ascites may be associated with changes in HCN2 of ICCs, which offers a potential therapeutic target for gastrointestinal dysmotility in advanced malignant ascites.

\section{Introduction}

Numerous advanced malignant abdominal tumors have been reported to lead to malignant ascites $(1,2)$, which can cause gastrointestinal dysmotility. The symptoms of gastrointestinal dysmotility consist of abdominal pain, distention, nausea, vomiting and constipation (3). It is important to identify the reason for gastrointestinal dysmotility caused by malignant ascites. Changes in the interstitial cells of Cajal (ICCs) are known to be partially responsible for malignant ascites-induced gastrointestinal dysmotility (4), but the mechanisms are not completely understood.

The excitation and contraction of gastrointestinal smooth muscle cells are regulated by slow-wave activity, which is a basic electrical rhythm of the gastrointestinal system (5). The ICCs act as pacemakers, and this mechanism is attributed to the activation of ion channels $(6,7)$, including $\mathrm{Ca}^{2+}$-activated chloride channels, non-selective cation channels and sodium channels (8-10). ICCs exhibit slow-wave activity and mediate basal electrical rhythms in the gastrointestinal tract $(11,12)$. However, little is known about the association between malignant ascites and ICCs. It was previously reported that malignant ascites reduces the number of ICCs, and it was demonstrated that gastrointestinal dysmotility induced by gastric cancer peritoneal metastasis was relevant to decreases in ICCs and disrupted the electrical rhythm (3).

Previously, numerous studies demonstrated that hyperpolarization-activated cyclic nucleotide-gated potassium channels (HCNs) exist in ICCs, and that these channels may be important regulators of the excitability and pacemaker activity of ICCs $(13,14)$. HCN channels are particular cation channels that participate in cell autonomy and excitability (15). These channels are activated by hyperpolarization and intracellular cyclic adenosine monophosphate (cAMP) (16). The HCN channel family comprises 4 members, designated HCN1-4, 
which are permeable to $\mathrm{Na}^{+}$and $\mathrm{K}^{+}(17)$. $\mathrm{HCN}$ channels activate T-type voltage-dependent $\mathrm{Ca}^{2+}$ channels via membrane depolarization, which alters intracellular $\mathrm{Ca}^{2+}$ concentrations (18).

The present study hypothesized that the small intestinal dysmotility caused by malignant ascites may be associated with changes in HCN2 channels on ICCs. Significant changes were identified in ICCs and HCN2 channels under the conditions of malignant ascites, which revealed a potential mechanism for malignant ascites-induced gastrointestinal motility dysfunction.

\section{Materials and methods}

Malignant ascites mouse model. Animal experiments were performed under the Rules and Regulations of the Animal Care and Use Committee at Harbin Medical University (Harbin, China; approval no., HMUIRB20140022). C57BL/6 mice (age, 4-6 weeks old; gender, male and female; weight, 16-20 g) were purchased from Biological Technology Development Co., Ltd. (Liaoning, China). Mice were group-housed under 12-h light/dark cycles and raised at a constant temperature of $26-28^{\circ} \mathrm{C}$, and they were given ad libitum access to food and water.

In total, 39 of $46 \mathrm{C} 57 \mathrm{BL} / 6$ mice were used to generate a model of malignant ascites via the administration of a $0.2 \mathrm{ml}$ intraperitoneal injection of mouse fore-stomach carcinoma (MFC) cells, MFC cells were obtained from the Type Culture Collection of the Chinese Academy of Science (Shanghai, China). Malignant ascites was successfully generated in 37 of the 39 mice on the ninth day subsequent to intraperitoneal injection. The control group (7 of 46 C57BL/6 mice) was treated with the same volume of physiological saline.

ICC isolation and culture. To isolate ICCs, a total of, 100 C57BL/6 wild-type mice (8-13 days old) were anesthetized with 3.5-5\% diethyl ether (Shanghai Heyi Chemical, Co., Ltd., Shanghai, China) and sacrificed through cervical dislocation. The intestines from $1 \mathrm{~cm}$ below the pyloric ring to the cecum were resected and opened along the mesenteric border. The intestinal mucosa was removed, and strips of muscle were collected. Muscle cells were dispersed via incubation in an enzyme solution composed of $1.3 \mathrm{mg} / \mathrm{ml}$ collagenase type II, $2 \mathrm{mg} / \mathrm{ml}$ bovine serum albumin (Roche Applied Science, Penzberg, Germany), $2 \mathrm{mg} / \mathrm{ml}$ trypsin inhibitor and $0.27 \mathrm{mg} / \mathrm{ml}$ adenosine triphosphate at $37^{\circ} \mathrm{C}$ for $15 \mathrm{~min}$. The cells were spun down at $1,249 \mathrm{xg}$ for $10 \mathrm{~min}$ at room temperature and suspensions were then plated onto sterile glass coverslips coated with murine collagen in M199 medium (HyClone, GE Healthcare Life Sciences, Logan, UT, USA). These isolated cells were subsequently co-cultured with malignant ascites in order to investigate the effect of malignant ascites on ICCs.

Intestinal myoelectrical activity. In total, 10 C57BL/6 mice (7 from malignant ascites group and 3 from control group) were anesthetized with $1 \%$ sodium amobarbital $(40 \mathrm{mg} / \mathrm{kg}$, New Asia Pharmaceutical, Shanghai, China) subsequent to a $12 \mathrm{~h}$ fasting period. A platinum electrode was placed on the muscular layer under the serosa through a $2-\mathrm{cm}$ midline abdominal incision. The following parameters were set: $200 \mu \mathrm{V}$ voltage; $1.0 \mathrm{sec} / \mathrm{div}$ time; and $30 \mathrm{~Hz}$ frequency. Recordings were performed for
20 min and saved. Groups of various electrical activities, including frequency, and maximum, minimum and average amplitude $(\mu \mathrm{V})$, were selected randomly and analyzed using RM6240 B/C Multi-Channel Physiological Signal Acquisition and Recorder System software version usb2.0Z(I) (Chengdu Instrument Factory, Chengdu, China).

Hematoxylin and eosin $(H \& E)$ staining and electron microscopy analysis. A total of $14 \mathrm{C} 57 \mathrm{BL} / 6$ mice intestinal samples (10 from malignant ascites group and 4 from control group) were collected immediately following sacrifice. The tissues were fixed for $24 \mathrm{~h}$ using $4 \%$ paraformaldehyde, and stained with $\mathrm{H} \& \mathrm{E}$ subsequent to dehydration, embedding and slicing (3-4 $\mu \mathrm{m}$ thickness). Structural and morphological changes were observed under a light microscope (Nikon Corporation, Tokyo, Japan). Images were captured using a conventional optical camera.

Samples were fixed with 3\% glutaraldehyde in PBS (pH 7.2) for $2 \mathrm{~h}$, and then rinsed with PBS, post-fixed in $1 \%$ osmium tetroxide for $2 \mathrm{~h}$ at $4^{\circ} \mathrm{C}$, dehydrated in a graded series of acetone and embedded in Epon 812 (EMS, Connecticut, USA). Ultrathin sections were cut at a thickness of 50-70 nm, which were subsequently double stained with uranyl acetate and lead citrate, and examined using an electron microscope (H-7650, Hitachi, Tokyo, Japan).

Immunofluorescence. ICCs and mice intestinal tissue frozen sections (including $10 \mathrm{C} 57 \mathrm{BL} / 6$ malignant ascites mice and 4 control mice) were fixed in $4 \%$ paraformaldehyde for $30 \mathrm{~min}$ and blocked with $2 \%$ goat serum (Beijing Solarbio Science \& Technology Co., Ltd., Beijing, China) in PBS containing $0.1 \%$ Triton-X for $1 \mathrm{~h}$. The primary antibodies consisted of anti-c-kit (dilution, 1:50; cat. no. B0813; Santa Cruz Biotechnology, Inc., Dallas, TX, USA) and anti-HCN2 (dilution, 1:50; cat. no. ab84817; Abcam, Cambridge, UK). The samples were incubated with the primary antibodies at $4^{\circ} \mathrm{C}$ overnight, washed twice with PBS and incubated with the fluorescein isothiocyanate (FITC)-labeled anti-rabbit secondary antibody (dilution, 1:100; cat. no. M0808; Vector Laboratories, Inc., Burlingame, CA, USA). The samples were then subsequently washed with PBS, counterstained with DAPI (Beyotime Institue of Biotechnology, Beijing, China) and finally examined using fluorescence microscopy (Nikon E800, Japan) at excitation wavelengths of 488 and $594 \mathrm{~nm}$.

Gene expression analysis. Total RNA, extracted from $15 \mathrm{C} 57 \mathrm{BL} / 6$ malignant ascites mice and 4 control mice, was isolated in the Super clean workbench, using TRIzol (Invitrogen; Thermo Fisher Scientific, Inc., Waltham, MA, USA). Upon mixing, RNA was extracted using chloroform. RNA samples were diluted in diethylpyrocarbonate (DEPC) -treated water subsequent to precipitation, dissolution and centrifugation at $6,288 \times \mathrm{g}$ for $5 \mathrm{~min}$, at $4^{\circ} \mathrm{C}$. In total, $1 \mathrm{mg}$ of DNase-treated RNA was reverse transcribed into complementary DNA (cDNA) using First-Strand Synthesis kit (Takara Bio, Inc., Otsu, Japan). Subsequently, $\sim 3.5 \mu 1$ oligo deoxythymidine, $3.5 \mu 1$ deoxynucleotides (dNTP), $2 \mu \mathrm{g}$ RNA and 19.25 $\mu \mathrm{l}$ DEPC-treated water were added to a $35 \mu \mathrm{l}$ buffer solution (10 mmol/l dNTP, RNA Polymerase, $\left.25 \mathrm{mmol} / 1 \mathrm{Mgcl}_{2}\right)$. Following pre-denaturation at $70^{\circ} \mathrm{C}$ for $3 \mathrm{~min}$, the mixture was 
placed on ice, and $7 \mu 15 \mathrm{X}$ buffer and $1.75 \mu 1$ Moloney murine leukemia virus reverse transcriptase was added. Primers were used to amplify the products under the following conditions: $42^{\circ} \mathrm{C} 1 \mathrm{~h}, 95^{\circ} \mathrm{C} 5 \mathrm{~min}$ and $4^{\circ} \mathrm{C}$ until use. The cDNA samples were stored at $-20^{\circ} \mathrm{C}$ until use.

Quantitative polymerase chain reaction (qPCR) analysis was performed in triplicate with Platinum SYBR Green qPCR Super Mix-UDG (Takara Bio, Inc.). The $20 \mu \mathrm{l}$ reaction solution contained $10 \mu$ l SYBR Premix Ex Taq (Takara Bio, Inc.), $1 \mu 1$ PCR forward primer, $1 \mu \mathrm{l}$ PCR reverse primer, $0.5 \mu$ l template DNA and $6 \mu \mathrm{l}$ DEPC-treated water. The reactions were conducted for 40 cycles under the following conditions: $95^{\circ} \mathrm{C}$ for $30 \mathrm{sec}, 95^{\circ} \mathrm{C}$ for $5 \mathrm{sec}$ and $60^{\circ} \mathrm{C}$ for $34 \mathrm{sec}$, on the LightCycler ${ }^{\circledR} 480$ Real-Time PCR System (Roche Applied Science). For the quantification of gene expression, GAPDH mRNA was used as the endogenous control. The relative expression levels of HCN2 and cAMP mRNA, normalized to GAPDH mRNA, were calucated using the $2^{-\Delta \Delta \mathrm{Cq}}$ value (19).

The primer sequences used in the present study are shown in Table I.

Flow cytometry analysis. ICCs isolated from C57BL/6 mice subsequent to being co-cultured with malignant ascites were cultured with Fluo-4 and acetoxymethyl/dimethyl sulfoxide (Beijing, China) at $37^{\circ} \mathrm{C}$ for $20 \mathrm{~min}$, and then incubated with Hanks' balanced salt solution supplemented with $1 \%$ fetal bovine serum (Gibco; Thermo Fisher Scientific, Inc.) at room temperature for $40 \mathrm{~min}$. Cells were washed with 4-(2-hydroxyethyl)-1-piperazineethanesulfonic acid-buffered saline and resuspended. $\mathrm{Ca}^{2+}$ ions were detected and analyzed after 10 min using flow cytometry (BD Biosciences, Franklin Lakes, NJ, USA) with an excitation wavelength of $494 \mathrm{~nm}$ and an emission wavelength of $516 \mathrm{~nm}$.

Statistical analysis. Comparisons between the control and malignant ascites groups were analyzed using a Student's t-test in SPSS version 17.0 (SPSS Inc., Chicago, IL, USA). P<0.05 was considered to indicate a statistically significant difference.

\section{Results}

Generation of malignant ascites model. C57BL/6 mice were used to generate a malignant ascites model via the administration of an intraperitoneal injection of MFC cells (Fig. 1A). The animals in the control group were treated with physiological saline. Ascites was generated on the ninth day subsequent to intraperitoneal injection. The mice were sacrificed between the 14th and 21st day subsequent to ascites generation according to their survival status (Fig. 1B). The fluid in the ascites was generally light pink (Fig. 1C) at the first extraction and gradually became bloody at later time-points (Fig. 1D and E).

Histological and dynamic changes in the small intestine induced by malignant ascites. Electrophysiology was performed to observe peristaltic changes in the intestine caused by malignant ascites. Compared with those in the control mice (Fig. 2Aa), the amplitude was lower and the frequency was slower in mice with malignant ascites (Fig. 2Ab), which suggests that malignant ascites led to a decline in the peristaltic function of the intestines. The histological characteristics of
Table I. Primer sequences used for quantitative polymerase chain reaction.

\begin{tabular}{lcl}
$\begin{array}{l}\text { Transcript } \\
\text { name }\end{array}$ & Primer & \multicolumn{1}{c}{ Sequence (5'-3') } \\
\hline HCN2 & F & CTGCGTGAGGAGATTGTGAA \\
& R & TTTGAGCTTTGTCAGCATGG \\
cAMP & F & GGTGCCAAGGATTGAAGAAG \\
& R & CTGCCCACTGCTAGTTTGG \\
GAPDH & F & AGAAGGTGGTGAAGCAGGCATC \\
& R & CGAAGGTGGAAGAGTGGGATTG
\end{tabular}

HCN2, hyperpolarization-activated cyclic nucleotide-gated potassium channel 2; cAMP, cyclic adenosine monophosphate; F, forward; $\mathrm{R}$, reverse.
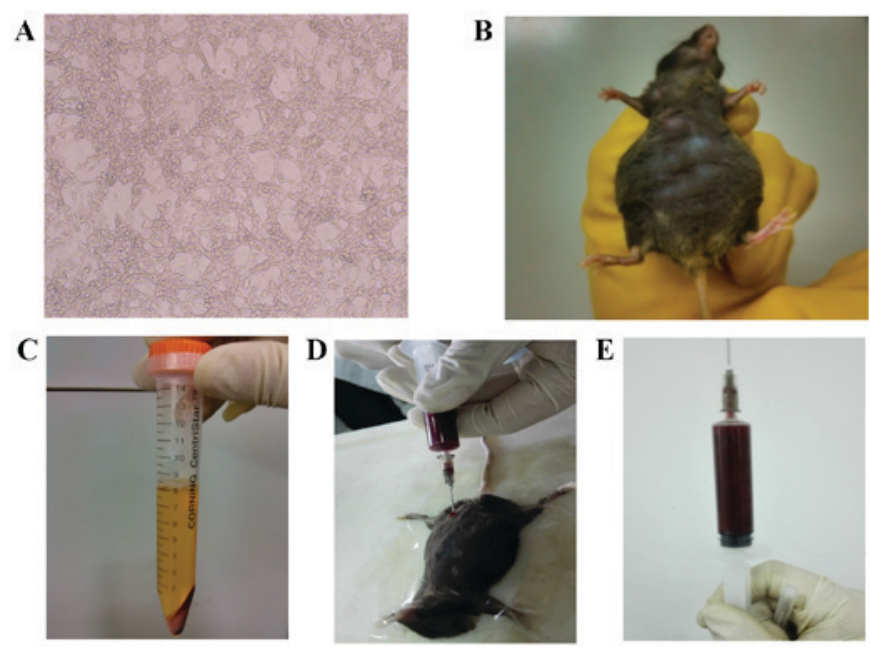

Figure 1. Generation of a malignant ascites model. (A) Mouse fore-stomach carcinoma cells exhibited slender morphology or the processes under an inverted microscope (magnification, x100). (B) Generation of an animal model of malignant ascites. (C) The first extraction of ascites fluid was pale pink. (D and E) The subsequent extraction of ascites fluid was bloody.

the intestines were compared between the malignant ascites and control groups. The intestinal villi were shorter and fewer in number under light microscopy, and the thickness of the intestinal muscularis was in homogeneous and hydropic in mice with malignant ascites (Fig. 2Ba). The morphology of the intestinal villi was intact, and the thickness of the intestinal muscularis was uniform in the control groups (Fig. 2Bb). These results suggest that the motility dysfunction induced by malignant ascites was associated with changes in the intestines.

Ultrastructural examinations revealed that ICC volume was reduced, their nuclei were clearly condensed and the number of cytoplasmic processes in ICCs was decreased, with few connections with other cells being observed in the malignant ascites group (Fig. 2Bc). In the control group, the ICCs exhibited well-centered nuclei and numerous cellular processes of ICCs that connected with other cells (Fig. 2Bd).

Generation of an animal model of peritoneal metastasis. A total of 28 out of the 39 mice underwent ascites extraction 

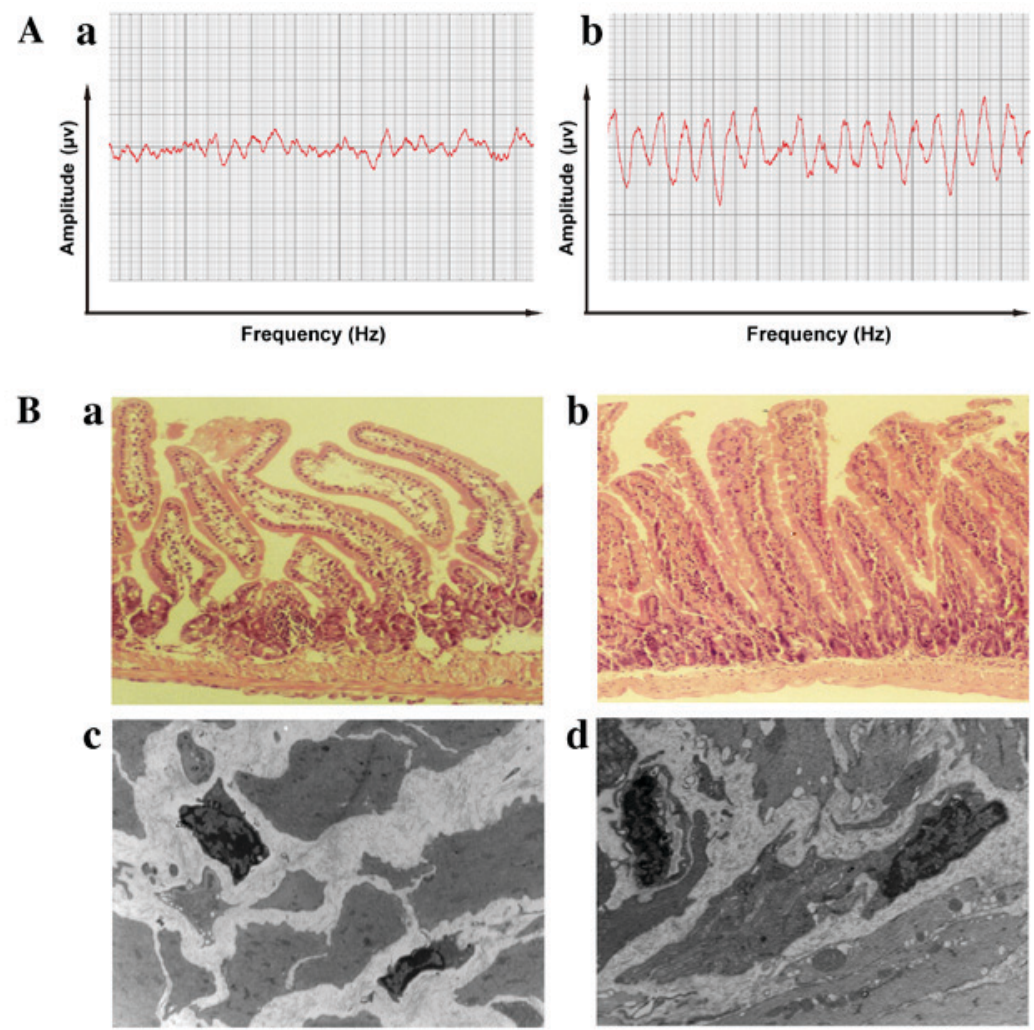

Figure 2. Electrophysiological and pathological characteristics of the intestine. (A)(a) The peristaltic amplitude in the intestine was reduced and irregular in mice with malignant ascites. (b) The control mice exhibited regular waves and stable frequencies. (B)(a) Light microscopy revealed that the intestinal villi were shorter and fewer in number, and the thickness of the intestinal muscularis was inhomogeneous and hydropic, in mice with malignant ascites compared with control mice (magnification, x200). (b) The morphology of the intestinal villi was intact and the thickness of the intestinal muscularis was uniform in the control group (magnification, x200). (c) Ultrastructurally, ICC volume was reduced, their nuclei were clearly condensed and the number of cytoplasmic processes in ICCs were decreased, with few connections with other cells being observed (magnification, x4,000). (d) In the control group, the ICCs exhibited well-centered nuclei and numerous processes that connected with other cells (magnification, $\mathrm{x} 4,000)$. ICC, interstitial cell of Cajal.

A
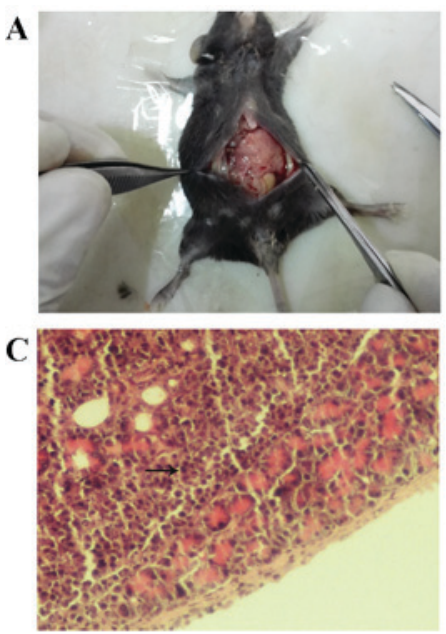

E

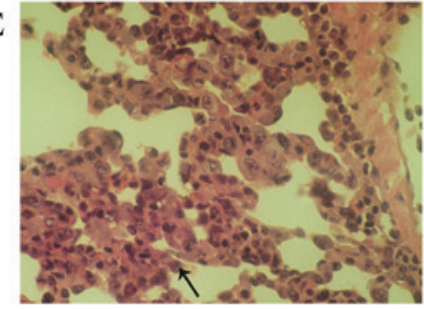

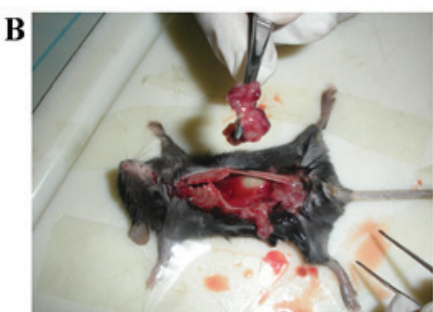

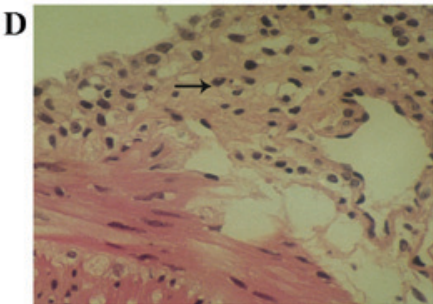

$\mathbf{F}$

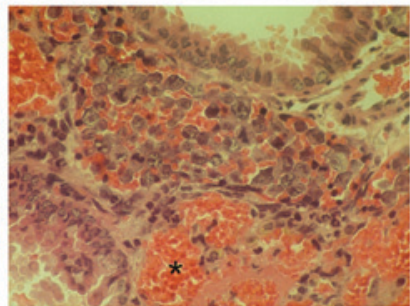

Figure 3. Generation of an animal model of peritoneal metastasis. (A) Tumors were observed in the abdominal cavities of the malignant ascites mice, and (B) the tumor sizes were similar to that of a grain of rice (about $\left.0.01 \mathrm{~cm}^{3}\right)$. (C and D) Light microscopy revealed that tumor cells invaded in the serosa of the intestine, omentum and pancreas and destroyed the surrounding tissues (magnification, $\mathrm{x} 400$ ). (E) Lung tissues with invasive tumor cells (magnification, $\mathrm{x} 400$ ) (F) were associated with a large hemorrhage (magnification, $\mathrm{x} 400$ ). 

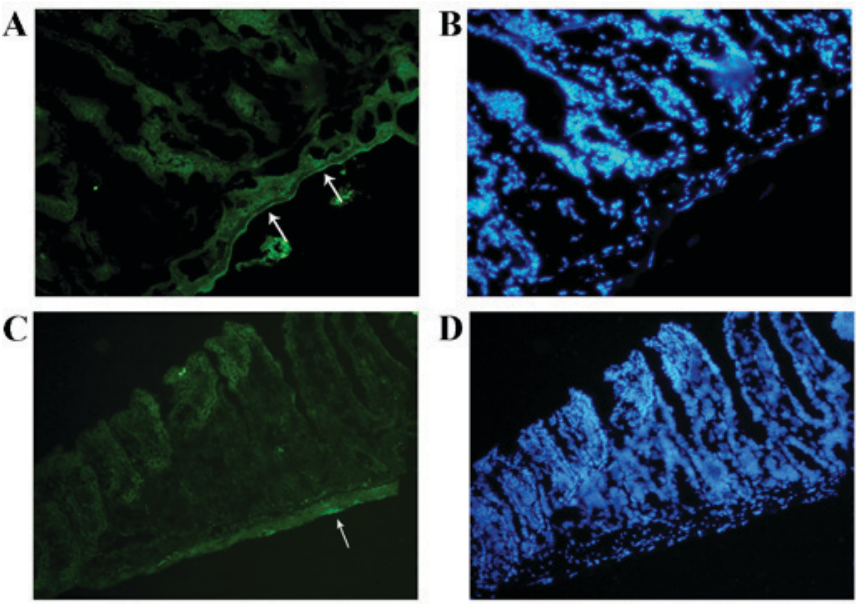

$\mathbf{E}$
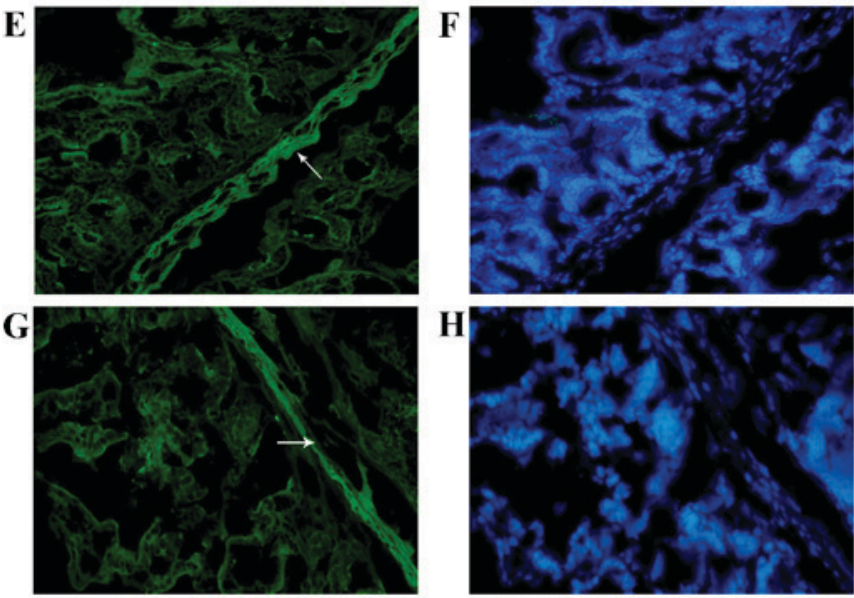

Figure 4. Immunofluorescence detection of c-kit and HCN2 in the intestine. (A) In the immunofluorescence analysis, c-kit expression in ICCs was shown as a bold line in the control groups (magnification, $\mathrm{x} 400$ ), and (C) c-kit expression was reduced in the mice with malignant ascites (magnification, $\mathrm{x} 400)$. (G) Immunofluorescence detection revealed no evident changes in $\mathrm{HCN} 2$ expression in the malignant ascites group (magnification, $\mathrm{x} 400$ ) compared with (E) the control group (magnification, x400). (B, H) However, the muscularis propria was significantly thinner in the malignant ascites group compared with that in the control group. (magnification, x400). HCN2, hyperpolarization-activated cyclic nucleotide-gated potassium channel 2.

and pathological examinations. Tumors were identified in the abdominal cavities of the malignant ascites mice. The size of the tumors was similar to a grain of rice $\left(\sim 1 \mathrm{~mm}^{3}\right.$; Fig. 3A and B). Light microscopy revealed that tumor cells (indicated by an arrow in the figure) invaded in the serosa of the intestine, omentum and pancreas and destroyed the surrounding tissues (Fig. 3C and D), which indicates successful generation of the malignant ascites model. In total, 11 of the 28 mice (39.28\%) exhibited invasive tumor cells, and 22 of the 28 mice $(78.57 \%)$ exhibited pulmonary metastases. Lung tissues with invasive tumor cells (Fig. 3E, arrow) were associated with a large hemorrhage (Fig. 3F, asterisk).

Effect of malignant ascites on ICCs and HCN2 in the intestines. Pacemaker cells and pacemaker channels are involved in changes in the intestinal peristaltic function (14). ICCs are key pacemaker cells in the small intestine (14). Therefore, immunofluorescence was used to investigate the ICCs in the intestines of the two groups examined in the present study. In control group, c-kit expression was shown as a bold line in

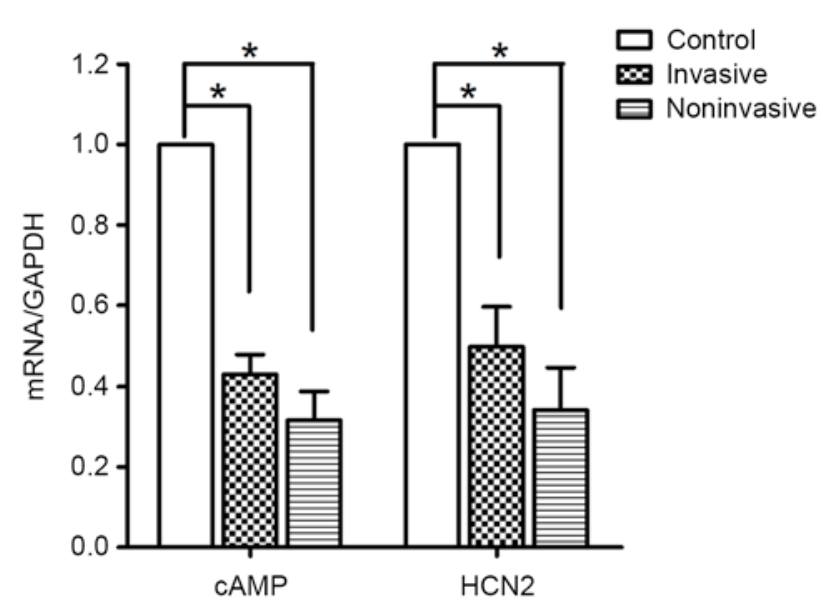

Figure 5. qPCR analyses of HCN2 and cAMP. qPCR analysis detected mRNA transcripts for HCN2 in the model and control groups. The mRNA transcript levels of HCN2 in the malignant ascites group were significantly lower compared with those in the control group $\left(\mathrm{P}=0.01,{ }^{*} \mathrm{P}<0.05\right)$. Additionally, the mRNA transcript levels for cAMP in the malignant ascites group were lower compared with those in the control group $\left(\mathrm{P}=0.01,{ }^{*} \mathrm{P}<0.05\right)$. qPCR, quantitative polymerase chain reaction; $\mathrm{HCN} 2$, hyperpolarization-activated cyclic nucleotide-gated potassium channel 2; cAMP, cyclic adenosine monophosphate; mRNA, messenger RNA.

the control group (Fig. 4A and B, arrow), but in the malignant ascites groups, the expression of c-kit was low, weak, spotty and granular in the muscularis layer in the malignant ascites groups (Fig. 4C and D, arrow). These changes in ICCs are consistent with a previous study by our group (4).

These results suggested that the gastrointestinal dysmotility induced by malignant ascites was relevant to the decreased expression and morphological changes observed in ICCs. Furthermore, the HCN2 channel is a pacemaker channel that is involved in gastrointestinal peristalsis (20). Compared with the control group (Fig. 4E and F, arrow), immunofluorescence analysis indicated that there were no evident changes in HCN2 in the malignant ascites group (Fig. 4G and H, arrow). By contrast, the muscularis propria was significantly thinner in the malignant ascites group compared with the control group.

qPCR detection of HCN2 expression. The present study performed qPCR to additionally elucidate changes in HCN2 expression. The qPCR analyses detected messenger RNA (mRNA) transcripts for HCN2 in the model and control groups. However, the mRNA transcript levels for HCN2 in the malignant ascites group were significantly lower compared with those in the control group ( $\mathrm{P}=0.01$; Fig. 5). The cAMP-dependent regulation of pacemaker activity may be mediated through HCN channels (21). Therefore, the expression of cAMP was also detected using qPCR. The mRNA transcript levels for cAMP in the malignant ascites group were lower compared with those in the control group ( $\mathrm{P}=0.01$; Fig. 5), similar to the results of HCN2 mRNA expression. These results suggest that the expression of HCN2 in ICCs is inhibited by malignant ascites, and that malignant ascites-induced gastrointestinal dysmotility is associated with decreased ICC number and reduced $\mathrm{HCN} 2$ expression.

Morphological analyses of ICCs and HCN2-mediated regulation of $\mathrm{Ca}^{2+}$ concentration in ICCs. The mechanism of 

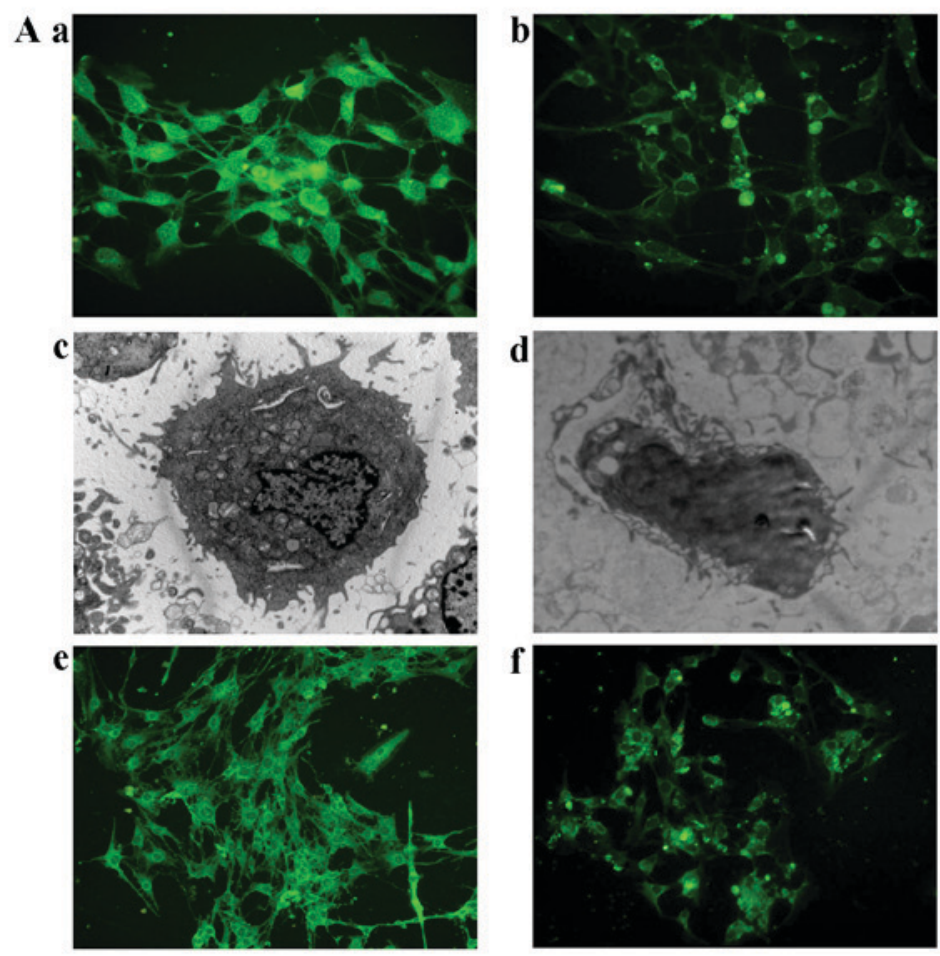

Figure 6. Morphological analyses of ICCs and $\mathrm{HCN} 2$ regulation of the $\mathrm{Ca}^{2+}$ concentration in ICCs. (A)(a) ICCs were analyzed using fluorescence and electron microscopy. Fluorescence microscopy revealed that c-kit was highly expressed in the ICC cytoplasm and membrane (magnification, $\mathrm{x} 400$ ). (c) Ultrastructural examination demonstrated that the ICCs were oval or circular and exhibited numerous slender processes on the surface. The nuclei were large, and numerous mitochondria were observed in the cytoplasm in the control group (magnification, x5,000). (b) Fluorescence (magnification, x400) and (d) electron microscopy (magnification, x 5,000) revealed apoptotic ICCs with a shrunken cell volume and condensed nuclei subsequent toco-culture with malignant ascites. Changes in HCN2 expression on ICCs were observed. (e) HCN2 expression was decreased in the malignant ascites group (magnification, $\mathrm{x} 400$ ) compared with (f) the control group (magnification, x400). (B) Flow cytometry analysis of $\mathrm{Ca}^{2+}$ concentrations. Flow cytometry revealed a significantly lower Ca ${ }^{2+}$ concentration in the malignant ascites group compared with that in the control group. The ratio of the $\mathrm{Ca}^{2+}$ concentration in the malignant ascites group to that in the control group is expressed as the mean \pm standard error of the mean. ${ }^{*} \mathrm{P}<0.05$, significant difference between the control and malignant ascites groups. The present study set a gate as M1 to represent FITC positive cells. ICC, interstitial cell of Cajal; HCN2, hyperpolarization-activated cyclic nucleotide-gated potassium channel 2; FITC, fluorescein isothiocyanate.

gastrointestinal dysmotility mediated by ICCs and HCN2 was additionally examined to determine the effect of malignant ascites on ICCs. ICCs isolated from C57BL/6 mice subsequent to being co-cultured with malignant ascites were detected using immunofluorescence and divided into 2 groups. One group was cultured with malignant ascites, while the other group served as the control group. Changes in c-kit and HCN2 expression on ICCs were observed. In the control group, c-kit was highly expressed in the cytoplasm and membranes of ICCs, which exhibited a slender morphology and evident connections with other cells (Fig. 6Aa). However, the ICCs were evidently smaller in the malignant ascites group, and c-kit expression appeared markedly decreased (Fig. 6Aa and b). Electron microscopy revealed that the ICCs were oval or circular and exhibited numerous slender processes on the surface. In the control group, the nuclei were large, and numerous mitochondria were observed in the cytoplasm (Fig. 6Ac). However, in the malignant ascites group the nuclei of ICCs were pyknotic, the number of cellular processes were reduced and the size of the ICCs was markedly reduced (Fig. 6Ad). HCN2 expression was also decreased in the malignant ascites group (Fig. 6Af) compared with that in the control group (Fig. 6Ae). These results suggested that malignant ascites decreased the expression of HCN2 on ICCs, thereby inducing gastrointestinal motility dysfunction.
HCN2 is a cation channel that exhibits pacing functions, and the release and reuptake of $\mathrm{Ca}^{2+}$ are linked to the generation of pacemaker activity (14). Therefore, the present study investigated $\mathrm{Ca}^{2+}$ concentrations using flow cytometry. The $\mathrm{Ca}^{2+}$ concentrations detected in the malignant ascites group $(82.60 \pm 2.21 \%)$ were significantly lower compared with those in the control group $(95.51 \pm 1.09 \% ; \mathrm{P}=0.01, \mathrm{P}<0.05$; Fig. $6 \mathrm{~B})$. These results suggested that malignant ascites reduced the $\mathrm{Ca}^{2+}$ concentration in $\mathrm{ICC}$, and that $\mathrm{HCN} 2$ regulated $\mathrm{Ca}^{2+}$ concentrations in ICCs and altered intestinal peristalsis in the malignant ascites group (We set a gate as M1 to represent FITC positive cells.).

\section{Discussion}

Patients with malignant ascites exhibit abdominal pain and abdominal distention caused by gastrointestinal dysmotility (22). The present data suggest that gastrointestinal dysmotility caused by malignant ascites is associated with $\mathrm{HCN} 2$ channels and $\mathrm{Ca}^{2+}$ concentrations in ICCs. The major findings of the present study were that malignant ascites reduced $\mathrm{HCN} 2$ expression and $\mathrm{Ca}^{2+}$ concentrations in ICCs and affected intestinal peristalsis.

The mechanisms underlying malignant ascites-induced gastrointestinal dysmotility are not clear, but our previous 
study suggests that pathological changes in ICCs are involved in this process (3). ICCs generate slow-wave activity and regulate gastrointestinal peristalsis (23). The stem cell factor (SCF)/c-kit signaling pathway is important in the loss of ICCs (24). A previous study indicated that SCF improves the function of ICCs and promotes gastrointestinal peristalsis (25). The present study additionally examined the mechanisms of malignant ascites-induced gastrointestinal dysmotility. The present data demonstrated that malignant ascites altered ICC morphology and triggered apoptosis. ICC nuclei were pyknotic, and cell processes were reduced in these cells. The pacemaker function of ICCs was also decreased. ICCs are pacemaker cells that generate electrical activity to drive contractility in the gastrointestinal tract via $\mathrm{Ca}^{2+}$ transients (26). Intracellular $\mathrm{Ca}^{2+}$ serves a critical role in the generation of pacemaker activity in ICCs and electrical rhythmicity in the gastrointestinal tract (27-29). Previous studies have suggested that slow-wave generation depends on T-type $\mathrm{Ca}^{2+}$ conductance, and that this T-type current is involved in the pacemaker activity of ICCs (30). Flow cytometry data demonstrated that $\mathrm{Ca}^{2+}$ concentrations were significantly reduced in malignant ascites, which suggests that malignant ascites reduce $\mathrm{Ca}^{2+}$ concentrations in ICCs in the intestine, and additionally inhibit action potential and slow waves in the intestine, as well as decelerating intestinal peristalsis.

HCN2 channels are cation channels that generate hyperpolarization-activated cation currents, which contribute to various physiological properties and functions, including pacemaker activity $(31,32)$. HCN channels are associated with spontaneous rhythmic activities, and regulate the excitability of vagal and spinal afferents, which participate in the generation of abdominal distention and abdominal pain (33). HCN channels are pacemaker channels that regulate gastrointestinal peristalsis (14). The present study demonstrated that malignant ascites reduced $\mathrm{HCN} 2$ expression. The $\mathrm{HCN}$ channel family consists of four homologous members (HCN1-HCN4). HCN2-positive neurons and their terminal endings are in physical proximity to the cellular network of ICCs (34). HCN channels are expressed in the heart and nervous system (35). HCN channels exist in the bladder, and affect bladder excitation via bladder ICCs (36). HCN channels also exist in the digestive system, including the stomach and colon of mice $(14,37)$. The present study isolated ICCs from intestines and observed HCN2 expression in the ICCs. Previous studies have demonstrated the importance of cAMP binding for $\mathrm{HCN}$ channel function $(15,37,38)$. The present study revealed that cAMP and HCN2 mRNA levels were reduced in the malignant ascites group. Therefore, the present study hypothesized that malignant ascites would reduce HCN2 expression, and that certain substances present in malignant ascites would reduce cAMP expression and HCN2 channels activity. Our previous study (4) revealed abundant inflammatory cells in malignant ascites, primarily consisting of mononuclear cells and T lymphocytes, which may affect cAMP and HCN2 expression.

In conclusion, the findings of the present study suggested that the small intestinal dysmotility caused by malignant ascites is associated with changes in HCN2 channels in ICCs, which offers a potential therapeutic target for gastrointestinal dysmotility in advanced malignant ascites.

\section{Acknowledgements}

The present study was supported by the National Natural Science Fund (grant no. 81372611), the National Natural Science Youth Fund (grant no. 81301750) and the Education Department of Heilongjiang Province key project (grant no. 12521z017).

\section{References}

1. Becker G, Galandi D and Blum HE: Malignant ascites: Systematic review and guideline for treatment. Eur J Cancer 42: 589-597, 2006.

2. Sangisetty SL and Miner TJ: Malignant ascites: A review of prognostic factors, pathophysiology and therapeutic measures. World J Gastrointest Surg 4: 87-95, 2012.

3. Zheng H, He Y, Tong J, Sun L, Yang D, Li H, Ao N, Jin X and Zhang Q: Is gastrointestinal dysfunction induced by gastric cancer peritoneal metastasis relevant to impairment of interstitial cells of Cajal? Clin Exp Metastasis 28: 291-299, 2011.

4. Li J, Kong D, He Y, Wang X, Gao L, Li J, Yan M, Liu D, Wang Y, Zhang L and Jin X: The impact of inflammatory cells in malignant ascites on small intestinal ICCs' morphology and function. J Cell Mol Med 19: 2118-2127, 2015.

5. Sanders KM, Ward SM and Koh SD: Interstitial cells: Regulators of smooth muscle function. Physiol Rev 94: 859-907, 2014.

6. Gomez-Pinilla PJ, Gibbons SJ, Bardsley MR, Lorincz A, Pozo MJ, Pasricha PJ, Van de Rijn M, West RB, Sarr MG, Kendrick ML, et al: Ano1 is a selective marker of interstitial cells of Cajal in the human and mouse gastrointestinal tract. Am J Physiol Gastrointest Liver Physiol 296: G1370-G1381, 2009.

7. Koh SD, Sanders KM and Ward SM: Spontaneous electrical rhythmicity in cultured interstitial cells of cajal from the murine small intestine. J Physiol 513: 203-213, 1998.

8. d'antonio C, Wang B, McKay C and Huizinga JD: Substance P activates a non-selective cation channel in murine pacemaker ICC. Neurogastroenterol Motil 21: 985-e79, 2009.

9. Huizinga JD, Zarate N and Farrugia G: Physiology, injury, and recovery of interstitial cells of Cajal: Basic and clinical science. Gastroenterology 137: 1548-1556, 2009.

10. Strege PR, Ou Y, Sha L, Rich A, Gibbons SJ, Szurszewski JH, Sarr MG and Farrugia G: Sodium current in human intestinal interstitial cells of Cajal. Am J Physiol Gastrointest Liver Physiol 285: G1111-G1121, 2003

11. Ward SM and Sanders KM: Involvement of intramuscular interstitial cells of Cajal in neuroeffector transmission in the gastrointestinal tract. J Physiol 576: 675-682, 2006.

12. Sanders KM and Ward SM: Interstitial cells of Cajal: A new perspective on smooth muscle function. J Physiol 576: 721-726, 2006.

13. O'Donnell AM, Coyle D and Puri P: Decreased expression of hyperpolarisation-activated cyclic nucletide-gated channel 3 in Hirschsprung's disease. World J Gastroenterol 21: 5635-5640, 2015

14. Shahi PK, Choi S, Zuo DC, Kim MY, Park CG, Kim YD, Lee J, Park KJ, So I and Jun JY: The possible roles of hyperpolatization-activated cyclic nucleotide channels in regulating pacemaker activity in colonic interstitial cells of Cajal. J Gastroenterol 49: 1001-1010, 2014.

15. Harzheim D, Pfeiffer KH, Fabritz L, Kremmer E, Buch T, Waisman A, Kirchhof P, Kaupp UB and Seifert R: Cardiac pacemaker function of $\mathrm{HCN} 4$ channels in mice is confined to embryonic development and requires cyclic AMP. EMBO J 27 : 692-703, 2008.

16. Zong X, Krause S, Chen CC, Krüger J, Gruner C, Cao-Ehlker X, Fenske S, Wahl-Schott $\mathrm{C}$ and Biel M: Regulation of hyperpolarization-activated cyclic nucleotide-gated (HCN) channel activity by cCMP. J Biol Chem 287: 26506-26512, 2012.

17. DiFrancesco JC and DiFrancesco D: Dysfunctional HCN ion channels in neurological diseases. Front Cell Neurosci 6: $174,2015$.

18. Bernard M, Dejos C, Berges T, Regnacq $M$ and Voisin P: Activation of rhodopsin gene transcription in cultured retinal precursors of chicken embryo: Role of $\mathrm{Ca}(2+)$ signaling and hyperpolarization-activated cation channels. J Neurochem 129: 85-98, 2014.

19. Livak KJ and Schmittgen TD: Analysis of relative gene expression data using real-time quantitative PCR and the 2(-Delta Delta C (T)) Method. Methods 25: 402-408, 2001. 
20. Pape HC: Queer current and pacemaker: The hyperpolarization-actived cation current in neurons. Annu Rev Physiol 58: 299-327, 1996.

21. DiFrancesco D and Tortora P: Direct activation of cardiac pacemaker channels by intracellular cyclic AMP. Nature 351: 145-147, 1991.

22. Chasen $M$ and Bhargava R: Gastrointestinal symptoms, electrogastrography, inflammatory makers, and PG-SGA in patients with advanced cancer. Support Care Cancer 20: 1283-1290, 2012.

23. Lee JC, Thuneberg L, Berezin I and Huizinga JD: Generation of slow waves in membrane potential is an intrinsic property of interstitial cells of Cajal. Am J Physiol 277: G409-G423, 1999.

24. Tan YY, Ji ZL, Zhao G, Jiang JR, Wang D and Wang JM: Decreased SCF/c-kit signaling pathway contributes to loss of interstitial cells of Cajal in gallstone disease. Int J Clin Exp Med 7: 4099-4106, 2014.

25. Kong D, Li J, Zhao B, Xia B, Zhang L, He Y, Wang X, Gao L, Wang Y, Jin X and Lou G: The effect of SCF and ouabain on small intestinal motility dysfunction induced by gastric cancer peritoneal metastasis. Clin Exp Metastasis 32: 267-277, 2015

26. Singh RD, Gibbons SJ, Saravanaperumal SA, Du P, Hennig GW, Eisenman ST, Mazzone A, Hayashi Y, Cao C, Stoltz GJ, et al: Anol, a $\mathrm{Ca}^{2+}$-activated $\mathrm{Cl}$ - channel, coordinates contractility in mouse intestine by $\mathrm{Ca}^{2+}$ transient coordination between interstitial cells of Cajal. J Physiol 592: 4051-4068, 2014

27. Ward SM, Ordog T, Koh SD, Baker SA, Jun JY, Amberg G, Monaghan K and Sanders KM: Pacemaking in interstitial cells of Cajal depends upon calcium handling by endoplasmic reticulum and mitochondria. J Physiol 525: 355-361, 2000.

28. Drumm BT, Sergeant GP, Hollywood MA, Thornbury KT, Matsuda TT, Baba A, Harvey BJ and McHale NG: The effect of high $[\mathrm{K}(+)]$ o on spontaneous $\mathrm{Ca}(2+)$ waves in freshly isolated interstitial cells of Cajal from the rabbit urethra. Physiol Rep 2: e00203, 2014.
29. Zhu MH, Sung TS, O'Driscoll K, Koh SD and Sanders KM: Intracellular $\mathrm{Ca}(2+)$ release from endoplasmic reticulum regulates slow wave currents and pacemaker activity of interstitial cells of Cajal. Am J Physiol Cell Physiol 308: C608-C620, 2015.

30. Zheng H, Park KS, Koh SD and Sanders KM: Expression and function of a T-type $\mathrm{Ca}^{2+}$ conductance in interstitial cells of Cajal of the murine small intestine. Am J Physiol Cell Physiol 306: C705-C713, 2014

31. Biel M, Schneider A and Wahl C: Cardiac HCN channels: Structure, function, and modulation. Trends Cardiovasc Med 12: 206-212, 2002

32. Notomi $\mathrm{T}$ and Shigemoto R: Immunohistochemical localization of Ih channel subunits, HCN1-4, in the rat brain. J Comp Neurol 471: 241-276, 2004

33. Wang YP, Sun BY, Li Q, Dong L, Zhang GH, Grundy D and Rong WF: Hperpolarization-activated cyclic nucleotide-gated cation channel subtypes differentially modulate the excitability of murine small intestinal afferents. World J Gastroenterol 18: 522-531, 2012.

34. Yang S, Xiong CJ, Sun HM, Li XS, Zhang GQ, Wu B and Zhou DS: The distribution of HCN2-positive cells in the gastrointestinal tract of mice. J Anat 221: 303-310, 2012.

35. Biel M, Wahl-Schott C, Michalakis S and Zong X: Hyperpolarization-activated cation channels: From genes to function. Physiol Rev 89: 847-885, 2009.

36. He P, Deng J, Zhong X, Zhou Z, Song B and Li L: Identification of a hyperpolarization-activated cyclic nucleotide-gated channel and its subtypes in the urinary bladder of the rat. Urology 79: 1411.e7-e13, 2012.

37. Herrmann S, Schnorr S and Ludwig A: HCN channels-modulators of cardiac and neuronal excitability. Int J Mol Sci 16 1429-1447, 2015.

38. Wainger BJ, DeGennaro M, Santoro B, Siegelbaum SA and Tibbs GR: Molecular mechanism of cAMP modulation of HCN pacemaker channels. Nature 411: 805-810, 2001. 